University of South Carolina

Scholar Commons

2006

\title{
An Experimental Investigation of Guided Wave Propagation in Corrugated Plates Showing Stop Bands and Pass Bands
}

Tribikram Kundu

Sourav Banerjee

University of South Carolina, United States, banerjes@cec.sc.edu

Kumar V. Jata

Follow this and additional works at: https://scholarcommons.sc.edu/emec_facpub

Part of the Acoustics, Dynamics, and Controls Commons, and the Applied Mechanics Commons

\section{Publication Info}

Published in The Journal of the Acoustical Society of America, Volume 120, Issue 3, 2006, pages \#1217-. (C)The Journal of the Acoustical Society of America 2006, Acoustical Society of America \& American Institute of Physics.

Kundu, T., Banerjee, S., \& Jata, K. V. (2006). An Experimental Investigation of Guided Wave Propagation in Corrugated Plates Showing Stop Bands and Pass Bands. The Journal of the Acoustical Society of America, 120 (3), \#1217. http://dx.doi.org/10.1121/1.2221534

This Article is brought to you by the Mechanical Engineering, Department of at Scholar Commons. It has been accepted for inclusion in Faculty Publications by an authorized administrator of Scholar Commons. For more information, please contact digres@mailbox.sc.edu. 


\title{
An experimental investigation of guided wave propagation in corrugated plates showing stop bands and pass bands
}

\author{
Tribikram Kundu ${ }^{\text {a) }}$ and Sourav Banerjee ${ }^{\text {b) }}$ \\ Department of Civil Engineering and Engineering Mechanics, University of Arizona, Tucson, Arizona 85721 \\ Kumar V. Jata ${ }^{\mathrm{c})}$ \\ Air Force Research Laboratory, AFRL/MLL, Wright Patterson Air Force Base, Ohio 45433
}

(Received 4 January 2006; revised 11 June 2006; accepted 13 June 2006)

\begin{abstract}
Nonplanar surfaces are often encountered in engineering structures. In aerospace structures, periodically corrugated boundaries are formed by friction-stir-welding. In civil engineering structures, rebars used in reinforced concrete beams and slabs have periodic surface. Periodic structures are also being used to create desired acoustic band gaps. For health monitoring of these structures, a good understanding of the elastic wave propagation through such periodic structures is necessary. Although a number of research papers on the wave propagation in periodic structures are available in the literature, no one experimentally investigated the guided wave propagation through plates with periodic boundaries and compared the experimental results with theoretical predictions as done in this paper. The experimental results clearly show that elastic waves can propagate through the corrugated plate (waveguide) for certain frequencies called "pass bands," and find it difficult to propagate for some other frequencies called "stop bands." Stop bands are found to increase with the degree of corrugation. Experimental results are compared with the theoretical predictions, and good matching is observed for plates with small degree of corrugation. Only two parameters - the depth of corrugation and the wavelength of the periodicity-are sufficient for modeling the elastic wave propagation in slightly corrugated plates. (C) 2006 Acoustical Society of America. [DOI: 10.1121/1.2221534]
\end{abstract}

PACS number(s): 43.20.Fn, 43.20.El, 43.20.Ye [LLT]

Pages: $1217-1226$

\section{INTRODUCTION}

The problem of elastic wave propagation in periodic structures has been investigated for over five decades. Brillouin wrote the classical book on this subject (1946). Dynamics of a wide variety of periodic structures has been presented in this book. Later, Mead and his co-workers (Mead, 1970, 1975, 1976, 1986; Mead and Markus, 1983; Mead and Bardell, 1987; Mead and Yaman, 1991) made significant contributions in this field of research. In these works, Mead et al. solved the elastodynamic problems involving periodically supported beams (Mead, 1970; Mead and Markus, 1983), periodic damped plates (Mead, 1976), damped plates with stiffeners (Mead, 1986; Mead and Yaman, 1991), and thin cylindrical shells with periodic circumferential stiffeners (Mead and Bardell, 1987). Like many other engineering problems, periodic structure problems have been also solved by the finite element method (Oris and Petyt, 1974). Following Brillouin's classical approach, recently Ruzzene and Baz (2000) analytically solved the one-dimensional problemcomposite rods with shape memory alloy inserts, periodically embedded in the base material of the rod. Interested readers are referred to the article by Mester and Benaroya (1995) for a comprehensive review of wave propagation problems in periodic and near-periodic structures.

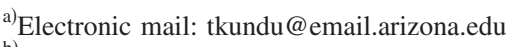

${ }^{\text {b) }}$ Electronic mail: sourav@email.arizona.edu

${ }^{c)}$ Electronic mail: kumar.jata@wpafb.af.mil
}

A common feature of the elastic wave propagation in periodic structures is the existence of distinct frequency bands-some of which allow wave propagation and others do not. Those frequencies, for which the waves can propagate through the structure, are called pass band frequencies, and other frequencies for which the waves are attenuated in the structure are called stop band frequencies or forbidden frequency bands (Vasseur et al., 1998).

In none of the articles referred to above has the elastic wave propagation through free plates with periodic surface boundaries been analyzed. In the above papers, the periodicity inside the materials or in the support condition has been considered. For example, Brillouin (1946) in his classical book presented the solution of wave propagation problem through one-, two-, and three-dimensional lattices of point masses with various degrees of complexity, Vasseur et al. (1998) studied the wave transmission through twodimensional binary solid/solid composite media composed of arrays of Duralumin cylindrical inclusions embedded in an epoxy resin matrix, Ruzzene and Baz (2000) solved the onedimensional problem of a composite rod with periodical insertions.

The problem of wave propagation in structures made of homogeneous materials, but having nonplanar boundaries and interfaces, has been the topic of investigation in the last three decades (Nayfeh et al., 1978; Boström, 1983, 1989; Sandström, 1986; Fokkema, 1980; Glass et al., 1983; ElBahrawy, 1994a, 1994b; Banerjee and Kundu, 2004; Declercq et al., 2005). Stop bands and pass bands of the 
Frequency response of Two $500 \mathrm{KHz}$ Non Focused Ultarsonic Transducers in water

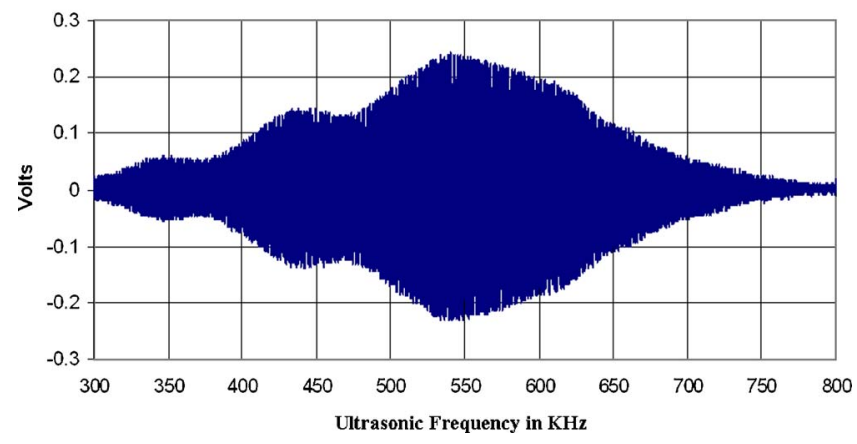

FIG. 1. (Color online) Received signal amplitude variation with frequency for the transmitter-receiver placed face to face.

Rayleigh-Lamb symmetric modes in sinusoidally corrugated waveguides have been studied by El-Bahrawy (1994a). Only recently have generalized dispersion equations for periodically corrugated waveguides been studied, and solutions for both symmetric and antisymmetric modes in a sinusoidally corrugated waveguide been presented (Banerjee and Kundu, 2006).

Although a number of theoretical papers have been published on elastic wave propagation in periodic structures, as mentioned above, very few experimental papers are available on this topic. The work of Vasseur et al. (1998) is the only two-dimensional experimental investigation available today. To the best of our knowledge, no investigator has yet experimentally measured the stop band and pass band frequencies in corrugated plates and compared the experimental results with the theoretical predictions as done in this paper.

\section{EXPERIMENT}

\section{A. Transducer characterization}

Two 1 in. diameter ultrasonic transducers were placed face to face. One transducer was excited by a signal frequency that continuously varied from $300 \mathrm{kHz}$ to $800 \mathrm{kHz}$, while the second transducer recorded the received signal. The recorded signal is shown in Fig. 1. Note that the transducer resonance frequency is close to $540 \mathrm{kHz}$, although the transducers were labeled as having $500 \mathrm{kHz}$ resonance frequency.

\section{B. Specimens}

Three aluminum plates were machined to produce three specimens with three different degrees of corrugation. A typical specimen is shown in Fig. 2. Figure 2(a) shows the full plate, Fig. 2(b) shows the side view of the corrugation, and Fig. 2(c) shows the period of corrugation $D$, highest plate thickness $H_{1}$, and lowest plate thickness $H_{2}$ in the corrugated region. Note that the average plate thickness $(2 h)$ in the corrugated region is equal to $\left(H_{1}+H_{2}\right) / 2$, and the corrugation depth $\varepsilon=\left(H_{1}-H_{2}\right) / 4$. These dimensions for the three specimens are given in Table I.

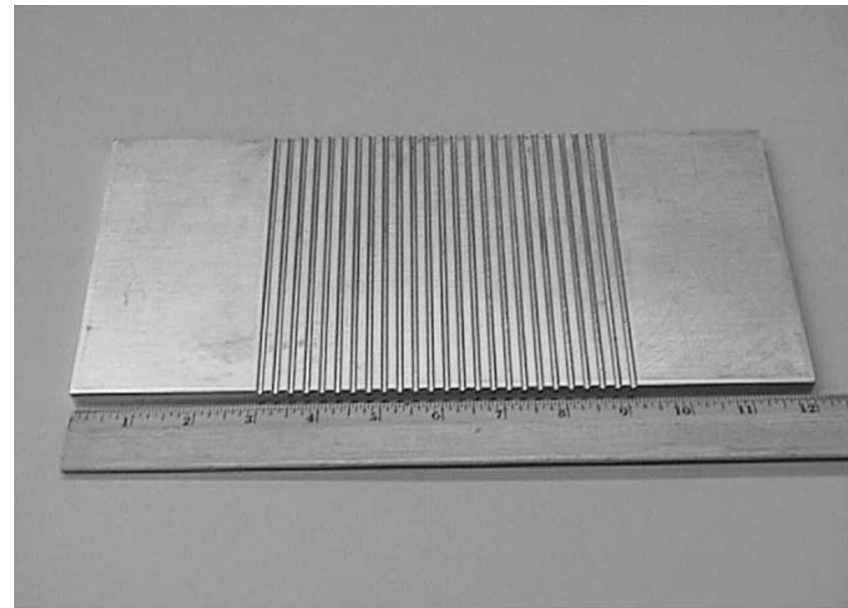

(a)

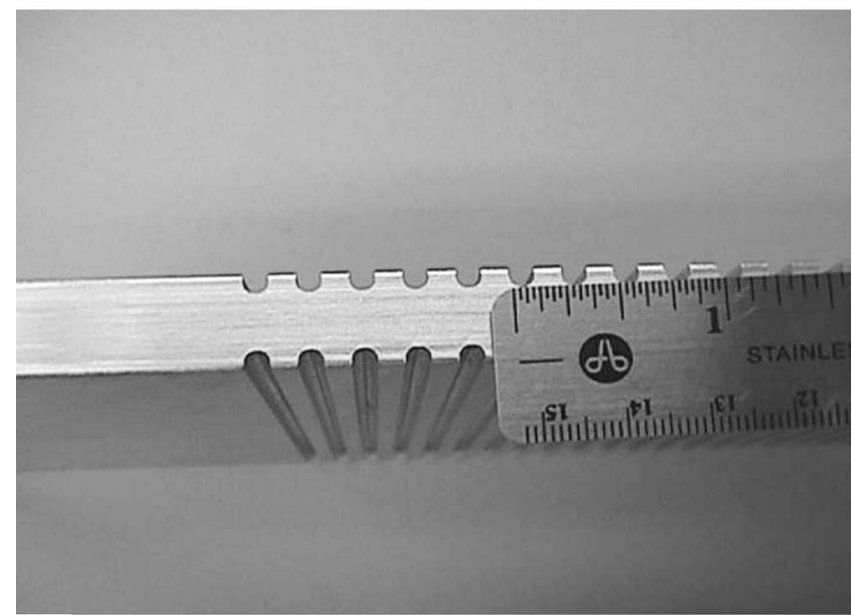

(b)

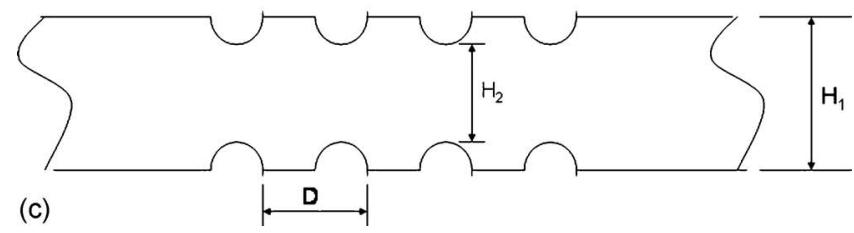

FIG. 2. Corrugated plate: (a) Top view, (b) side view, and (c) side view showing different dimensions.

\section{Experimental setup}

Two transducers are placed in the pitch-catch arrangement over the aluminum plate as shown in Fig. 3. Transducer $T$ acts as the transmitter and the second transducer $R$ acts as the receiver. Two transducers are inclined at an angle $\theta$ (clockwise and counterclockwise) with respect to the vertical axis as shown. The transducers are placed at a face to face distance of " $d$ " and a height " $h$ " above the aluminum plate. Transducers and the plate are immersed in water, which acts as the coupling fluid between the transducers and the plate-so that the ultrasonic energy can easily propagate from the transmitter to the plate and from the plate to the receiver. If the distance $d$ is set such that the direct reflected beam (shown by dashed line in Fig. 3) cannot reach the receiver, then the ultrasonic energy must propagate through the plate for a length $g_{1}$ as the guided wave (shown by the bold arrow in Fig. 3) before leaking back into the coupling fluid and reaching the receiver $R$. 
TABLE I. Dimensions of three corrugated plate specimens. All dimensions are given in in. and mm; mm values are given in parentheses.

\begin{tabular}{|c|c|c|c|c|c|c|c|}
\hline $\begin{array}{l}\text { Specimen } \\
\text { No. }\end{array}$ & $\begin{array}{c}H_{1} \\
(2 h+2 \varepsilon)\end{array}$ & $\begin{array}{c}H_{2} \\
(2 h-2 \varepsilon)\end{array}$ & $D$ & $\begin{array}{c}2 h \\
\left(H_{1}+H_{2}\right) / 2\end{array}$ & $\begin{array}{c}\varepsilon \\
\left(H_{1}-H_{2}\right) / 4\end{array}$ & $2 h / D$ & $\varepsilon / D$ \\
\hline 1 & $\begin{array}{c}0.5 \\
(12.7)\end{array}$ & $\begin{array}{c}0.416 \\
(10.57)\end{array}$ & $\begin{array}{l}0.425 \\
(10.8)\end{array}$ & $\begin{array}{c}0.458 \\
(11.63)\end{array}$ & $\begin{array}{l}0.021 \\
(0.53)\end{array}$ & 1.078 & 0.049 \\
\hline 2 & $\begin{array}{c}0.5 \\
(12.7)\end{array}$ & $\begin{array}{c}0.3 \\
(7.62)\end{array}$ & $\begin{array}{c}0.37 \\
(9.40)\end{array}$ & $\begin{array}{c}0.4 \\
(10.16)\end{array}$ & $\begin{array}{c}0.05 \\
(1.27)\end{array}$ & 1.081 & 0.135 \\
\hline 3 & $\begin{array}{c}0.5 \\
(12.7)\end{array}$ & $\begin{array}{l}0.187 \\
(4.75)\end{array}$ & $\begin{array}{c}0.38 \\
(9.65)\end{array}$ & $\begin{array}{l}0.344 \\
(8.74)\end{array}$ & $\begin{array}{l}0.078 \\
(1.98)\end{array}$ & 0.905 & 0.205 \\
\hline
\end{tabular}

\section{Experimental results}

Experiments are carried out for two different angles of incidence, $\theta=25^{\circ}$ and $30^{\circ}$. These two angles are selected because for these inclination angles relatively strong guided waves could be generated in the corrugated plate in the frequency range of our interest. Experimental results for these two sets of incident angles are described in detail below.

\section{Experimental results for $25^{\circ}$ and $30^{\circ}$ angles of incidence}

Two transducers $T$ and $R$, of 1 in. $(25.4 \mathrm{~mm})$ diameter, are placed above the smooth portion of the aluminum plate which is 0.5 in. $(12.7 \mathrm{~mm})$ thick. First, the transducers are positioned such that the directly reflected beam (shown by dashed line in Fig. 3) can reach the receiver $R$. This is the case when $h=3$ in. $(76.2 \mathrm{~mm})$ and $d=2.8$ in. $(71.1 \mathrm{~mm})$. The received signal strength as a function of the frequency for this transducer-receiver arrangement is shown in Fig. 4. Note that Figs. 1 and 4 are almost identical. Therefore, the receiving signal characteristics are not altered significantly when the transmitter and receiver are placed in the pitch-catch arrangement-with the receiver receiving the direct reflected beam. The received signal is plotted after attenuating the signal by a $37 \mathrm{~dB}$ attenuator. When $h$ is reduced to $2.5 \mathrm{in}$. $(63.5 \mathrm{~mm})$ and $d$ is proportionately reduced to $2.3 \mathrm{in}$. $(58.4 \mathrm{~mm})$, then the reflected beam showed similar strength variation with frequency.

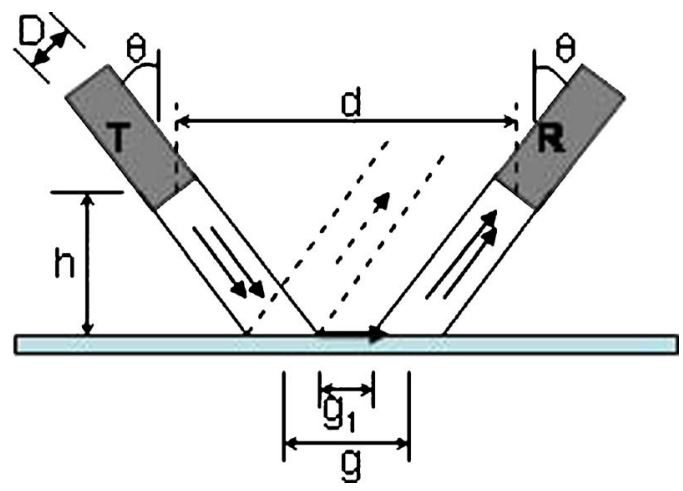

FIG. 3. Schematic of the transmitter $(T)$, receiver $(R)$ and the plate specimen arrangement. The direct reflected beam is shown by dashed lines. The receiver is placed beyond the direct reflection zone to detect the leaky guided waves.
Keeping $h$ fixed at 2.5 in. $(63.5 \mathrm{~mm})$ when the transducer spacing is increased to $4.25 \mathrm{in}$. (108 $\mathrm{mm})$, the received signal voltage versus frequency plot is changed significantly-as shown in Fig. 5. We will refer to the received signal voltage versus frequency plots as $V(f)$ curves. The $V(f)$ curve of Fig. 5 is plotted after attenuating the received signal by a $28 \mathrm{~dB}$ attenuator. Note that the peak near $540 \mathrm{kHz}$, observed in Figs. 1 and 4, is no longer present in Fig. 5. Also, two peaks of Fig. 5, near $430 \mathrm{kHz}$ and $645 \mathrm{kHz}$, are absent in Figs. 1 and 4. It will be shown later that these two peaks correspond to two Lamb wave modes in the plate. A simple calculation with transducer diameter $D=1 \mathrm{in}$. $(25.4 \mathrm{~mm})$, transducer spacing $d=4.25$ in. $(108 \mathrm{~mm})$, height $h=2.5 \mathrm{in} .(63.5 \mathrm{~mm})$, and transducer inclination angle $\theta$ $=25^{\circ}$ gives $g$ (see Fig. 3$)=1.918$ in. $(48.72 \mathrm{~mm})$ and $g_{1}$ (see Fig. 3) $=0.815$ in. $(20.7 \mathrm{~mm})$. Since $g_{1}$ is nonzero, the direct reflected beam cannot reach the receiver. Therefore, the ultrasonic energy must propagate through the plate as guided waves-for a certain distance greater than $g_{1}$ before leaking into the coupling fluid and being received by the receiver. It will be shown later that two frequencies, $430 \mathrm{kHz}$ and $645 \mathrm{kHz}$, generate two guided wave modes for transducer inclination angle $\theta=25^{\circ}$.

When the smooth plate is replaced by an aluminum plate with small corrugation $(\varepsilon / D=0.049$, Specimen 1 in Table I),

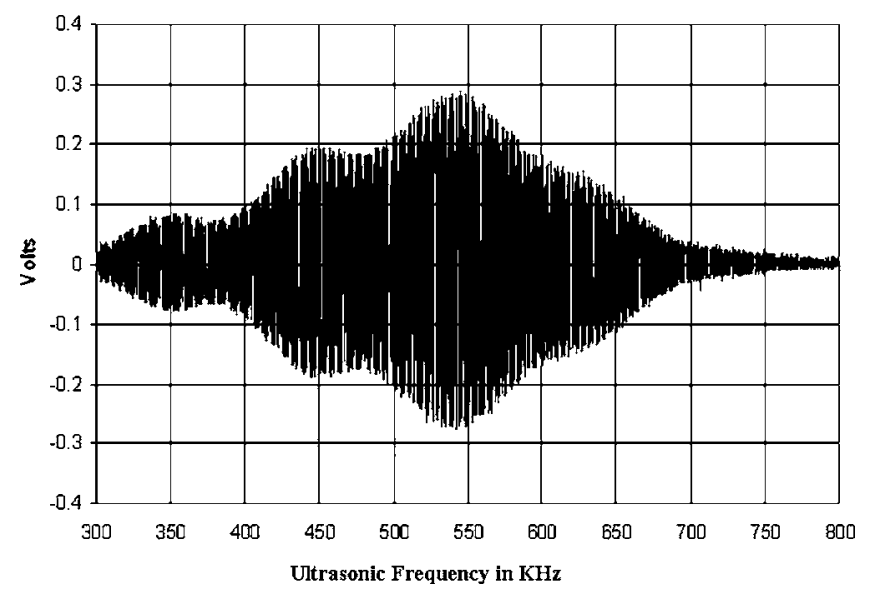

FIG. 4. Received signal voltage amplitude versus signal frequency curve, or $V(f)$ curve, for a smooth plate specimen when the receiver is placed in the direct reflection zone marked by dashed lines in Fig. 3. Note the similarities between Figs. 1(b) and 4. [For this figure, $\theta=25^{\circ}, h=3$ in. $(76.2 \mathrm{~mm}), d$ $=2.8$ in. $(71.1 \mathrm{~mm})$, and the signal attenuation is $37 \mathrm{~dB}$. A similar plot is obtained for $h=2.5 \mathrm{in}$. $(63.5 \mathrm{~mm})$ and $d=2.3 \mathrm{in}$. $(58.4 \mathrm{~mm})]$. 


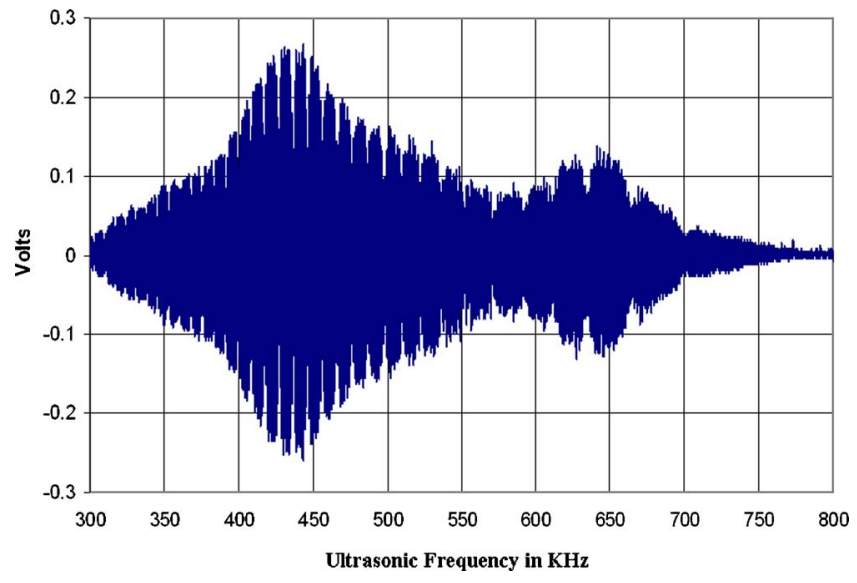

FIG. 5. (Color online) $V(f)$ curve for a smooth plate specimen when the receiver is placed beyond the direct reflection zone as shown in Fig. 3. Note the changes in the $V(f)$ curves of Figs. 4 and 5 in spite of the fact that the plate specimens for both figures are the same; the only difference is the horizontal distance (d) between the two transducers. For Fig. 5, the distance $d$ is greater. [For this figure, $\theta=25^{\circ}, h=2.5$ in. $(63.5 \mathrm{~mm}), d=4.25 \mathrm{in}$ $(108 \mathrm{~mm})$, and the signal attenuation is $28 \mathrm{~dB}$ ].

the $V(f)$ curve obtained for the setting $h=3$ in. $(76.2 \mathrm{~mm})$ and $d=7$ in. $(177.8 \mathrm{~mm})$ is shown in Fig. 6(a). For the transducer spacing $d=7$ in., the distance traveled by the guided wave in the corrugated plate is significantly greater than that for Fig. 5. Naturally, the received signal in Fig. 6(a) is much weaker than that in Fig. 5. Only an attenuation of strength $16 \mathrm{~dB}$ is applied to the received signal before plotting it in Fig. 6(a); while for Fig. 5, it was $28 \mathrm{~dB}$.

A comparison between Figs. 6(a) and 4 shows some similarities between these two $V(f)$ curves-both have peaks between 500 and $550 \mathrm{kHz}$ and the signal strength gradually decays to a very small value at low $(\sim 300 \mathrm{kHz})$ and high $(\sim 800 \mathrm{kHz})$ frequencies. However, a closer inspection also reveals some clear distinctions that will be discussed later.

Keeping all parameters $(h, d, \theta)$ unchanged, Specimen 1 is then replaced by Specimen 2 and finally by Specimen 3 . The $V(f)$ curve for Specimen 2 (medium corrugation, $\varepsilon / D$ $=0.135$ ) is shown in Fig. 6(b), and for Specimen 3 (large corrugation, $\varepsilon / D=0.205)$ is shown in Fig. 6(c). To maintain the numerical value of the $V(f)$ peaks close to 0.3 in all plots, a $14 \mathrm{~dB}$ attenuator is used for Fig. 6(b), and an $18 \mathrm{~dB}$ attenuator is used for Fig. 6(c). Comparison of these two figures with Fig. 4 shows some distinctive features that are discussed later.

Similar experiments with the same three corrugated plate specimens are carried out again for the $30^{\circ}$ angle of incidence and $V(f)$ curves for the three plates are recorded. Three $V(f)$ curves for the three corrugated plates for $30^{\circ}$ angle of incidence are shown in Figs. 7(a)-7(c).

\section{Distinctive features of $V(f)$ curves of corrugated plates}

A comparison of Figs. 4 and 7(a) reveals that, in Fig. 4, the signal strength is the maximum near $540 \mathrm{kHz}$ and it decays almost monotonically for both higher and lower frequencies with a couple of local minima observed near 380 and $480 \mathrm{kHz}$, while that is not the case in Fig. 7(a). Although

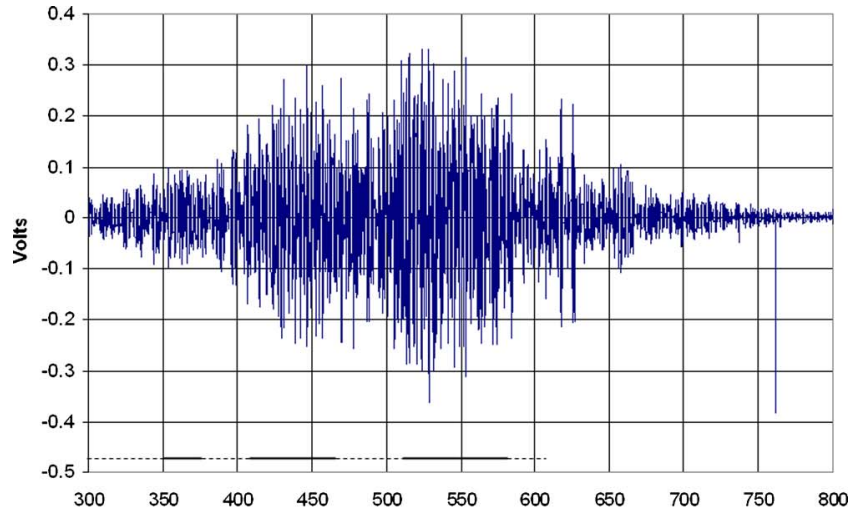

(a)

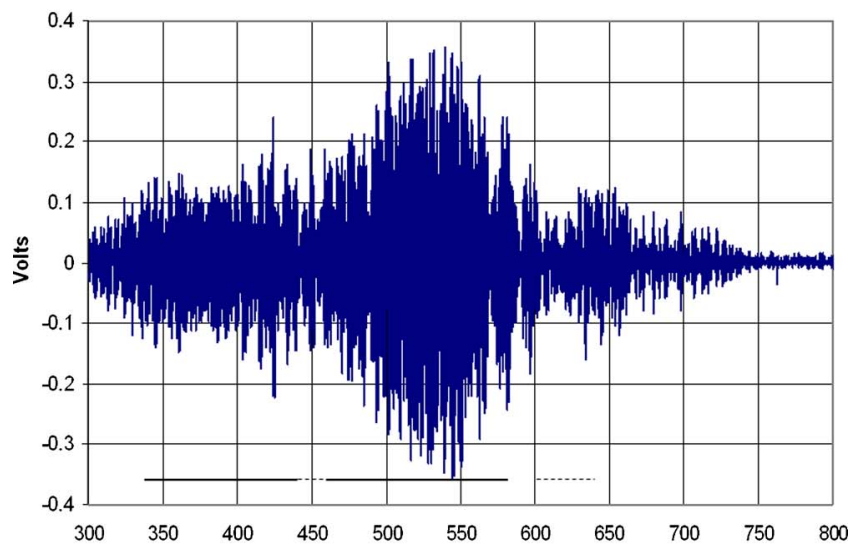

(b)

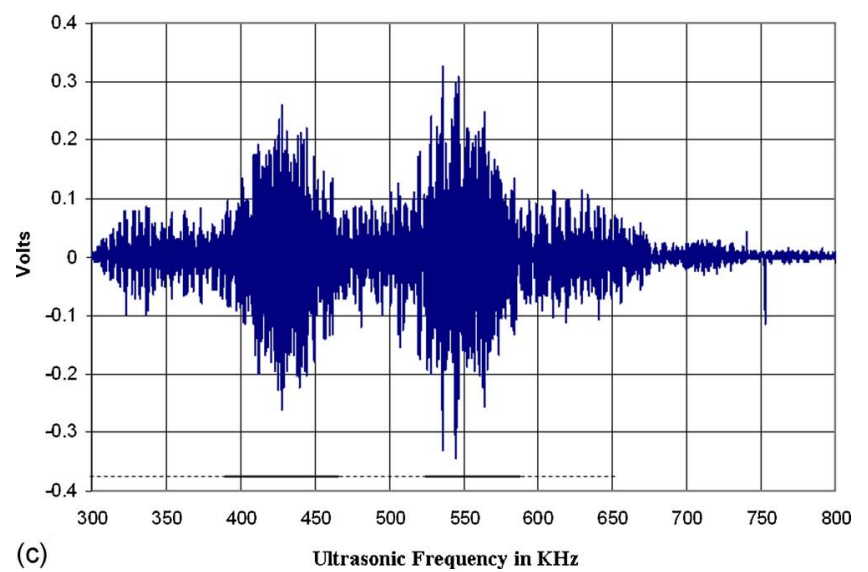

FIG. 6. (Color online) $V(f)$ curves for three corrugated plate specimens when the transducer inclination angle is $\theta=25^{\circ}$ and the receiver is placed beyond the direct reflection zone as shown in Fig. 3. (a) $V(f)$ curve for Specimen No. 1 (low corrugation, see Table I) when $h=3$ in. $(76.2 \mathrm{~mm}$ ), $d=7$ in. $(177.8 \mathrm{~mm})$, and the signal attenuation is $16 \mathrm{~dB}$. (b) $V(f)$ curve for Specimen No. 2 (medium corrugation, see Table I) when $h=3$ in. (76.2 mm), $d=7$ in. $(177.8 \mathrm{~mm})$, and the signal attenuation is $14 \mathrm{~dB}$. (c) $V(f)$ curve for Specimen No. 3 (large corrugation, see Table I) when $h$ $=3$ in. $(76.2 \mathrm{~mm}), d=7$ in. $(177.8 \mathrm{~mm})$, and the signal attenuation is $18 \mathrm{~dB}$.

the $V(f)$ amplitude envelope has a decaying trend for both higher and lower frequencies, this trend is not as monotonic as in Fig. 4. Clearly, in Fig. 7(a), the amplitude envelope has two noticeable dips (almost global minima) near 380 and $480 \mathrm{kHz}$, as shown by dashed curved line in Fig. 7(a). A few other smaller dips may be noticed in the amplitude envelope, but the two strongest dips are near 380 and $480 \mathrm{kHz}$. Note 


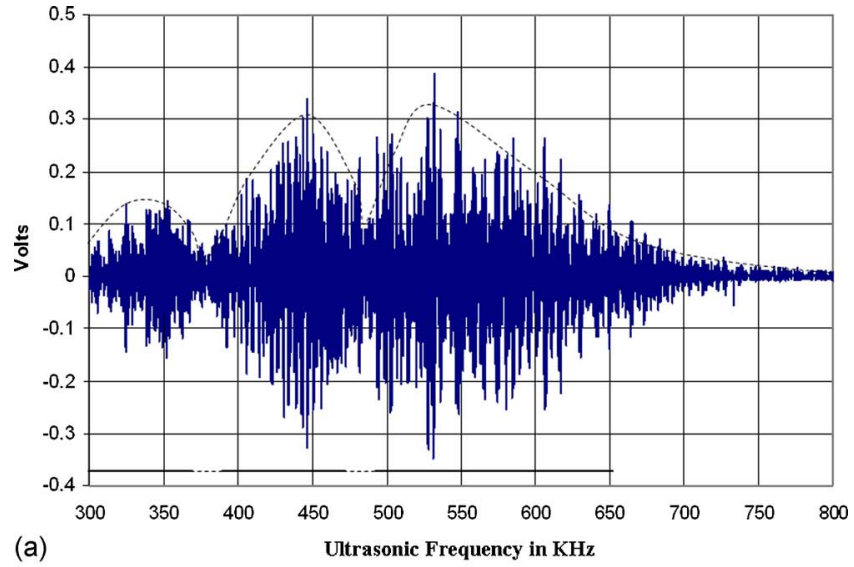

(a)
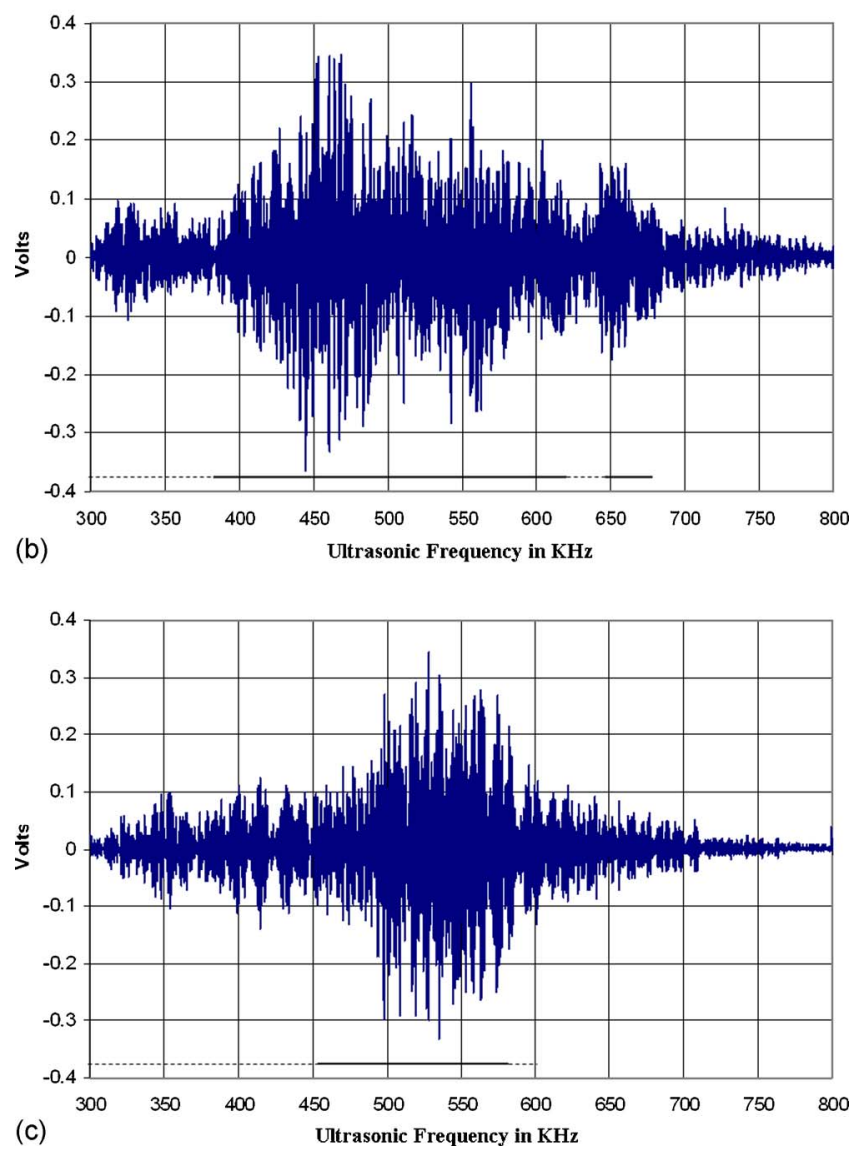

FIG. 7. $V(f)$ curves for three corrugated plate specimens when the transducer inclination angle $\theta=30^{\circ}$ and the receiver is placed beyond the direct reflection zone as shown in Fig. 3. (a) $V(f)$ curve for Specimen No. 1 (low corrugation, see Table I) when $h=2.25 \mathrm{in} . \quad(57.2 \mathrm{~mm}), d=7.5 \mathrm{in}$. $(190.5 \mathrm{~mm}$ ), and the signal attenuation is $14 \mathrm{~dB}$. (b) $V(f)$ curve for Specimen No. 2 (medium corrugation, see Table I) when $h=2.25$ in. $(57.2 \mathrm{~mm}$ ), $d=7.5 \mathrm{in}$. (190.5 mm), and the signal attenuation is $10 \mathrm{~dB}$. (c) $V(f)$ curve for Specimen No. 3 (large corrugation, see Table I) when $h=2.25$ in. $(57.2 \mathrm{~mm}), d=7.5 \mathrm{in}$. $(190.5 \mathrm{~mm})$, and the signal attenuation is $15 \mathrm{~dB}$.

that the propagating signal amplitude is very small in the frequency ranges of $370-390 \mathrm{kHz}$ and $470-490 \mathrm{kHz}$. Clearly, the ultrasonic signal finds it difficult to propagate in these two frequency ranges. The frequency bandwidths that block the ultrasonic wave propagation through the plate are called "stop bands" and the frequency bandwidths that do not cause such an obstruction to the wave propagation are called "pass bands." Therefore, for Specimen 1, for a $30^{\circ}$ angle of incidence, the stop bands are $370-390 \mathrm{kHz}$ and $470-490 \mathrm{kHz}$, while the frequency bandwidths of $300-370 \mathrm{kHz}, 390-470 \mathrm{kHz}$, and $490-650 \mathrm{kHz}$ constitute the pass bands. Near the bottom of Fig. 7(a), continuous and dashed horizontal lines are used to mark the pass band and stop band regions, respectively. Similarly, in Figs. 7(b), 7(c), and 6(a)-6(c) pass bands and stop bands are marked by continuous and dashed lines, respectively. In some figures, clear distinctions exist between the signals in pass band and stop band regions. For example, in Fig. 6(c), signals in the pass band zones are significantly stronger than those in the stop band zones. However, in some other figures, such as in Fig. 7 (a), the signal strength variations in these two regions are not that distinct. In some cases, logical judgments have been used to decide pass band and stop band regions. For example, in Fig. 7(c), one can see that the signal strength is weak in the region from 300 to $490 \mathrm{kHz}$, and strong between 490 and $580 \mathrm{kHz}$. However, we denoted the stop band from 300 to $450 \mathrm{kHz}$ instead of $490 \mathrm{kHz}$ because the signal strength starts to increase after $450 \mathrm{kHz}$ in Fig. 7(c); while in Fig. 4 (the flat plate case), the signal strength decreases from 450 to $480 \mathrm{kHz}$. Therefore, the corrugated surface is probably not creating a stop band between 450 and $490 \mathrm{kHz}$. It should be mentioned here that such subjective judgments and ambiguities may be overcome by employing sophisticated signal processing techniques, which can compare the strength of the received signals in different frequency ranges for the corrugated plates with those for the smooth plates and face to face orientations of the transducers.

Stop band and pass band frequencies for the three plates, obtained for $30^{\circ}$ and $25^{\circ}$ angles of incidence, are shown by continuous and dashed lines in Figs. 6 and 7, and their values are listed in Table II.

\section{E. Dispersion curves for smooth plates}

Before analyzing and understanding the experimental data for the corrugated plates, given in Figs. 6 and 7 and summarized in Table II, it is necessary to investigate first if the $V(f)$ curve for the smooth plate (Fig. 5) is reliable; in other words, whether the peaks of the $V(f)$ curve for the smooth plate-for which the guided wave propagation theory is well developed-appear at the right places. Figure 5 shows its two peaks near $430 \mathrm{kHz}$ and $645 \mathrm{kHz}$; these peaks are not present in Fig. 4. Do these peaks correspond to the Lamb wave modes generated in the plate? To investigate this, the dispersion curves for the aluminum plate are theoretically computed. The $P$-wave speed $\left(c_{P}\right)$ in aluminum is $6.2 \mathrm{~km} / \mathrm{s}$, its $S$-wave speed $\left(c_{S}\right)$ is $3 \mathrm{~km} / \mathrm{s}$, and density $(\rho)$ is $2.7 \mathrm{gm} / \mathrm{cc}$. The plate thickness is $12.7 \mathrm{~mm}$.

Lamb wave dispersion curves for a homogeneous isotropic elastic plate are obtained from the well-known dispersion equations [Kundu, 2004]: 
TABLE II. Stop band and pass band frequencies in $\mathrm{kHz}$ for two striking angles and three corrugated plate specimens whose dimensions are given in Table I.

\begin{tabular}{|c|c|c|c|c|c|c|}
\hline \multirow{2}{*}{$\begin{array}{l}\text { Striking } \\
\text { angle }\end{array}$} & \multicolumn{2}{|c|}{ Specimen No. 1} & \multicolumn{2}{|c|}{ Specimen No. 2} & \multicolumn{2}{|c|}{ Specimen No. 3} \\
\hline & Stop band & Pass band & Stop band & Pass band & Stop band & Pass band \\
\hline & $370-390$ & $300-370$ & $300-380$ & $380-620$ & $300-450$ & $450-580$ \\
\hline \multirow[t]{3}{*}{$30^{\circ}$} & $470-490$ & $390-470$ & $620-645$ & $645-680$ & $580-600$ & \\
\hline & & $490-650$ & & & & \\
\hline & $300-350$ & $350-375$ & $440-460$ & $340-440$ & $300-390$ & $390-470$ \\
\hline \multirow[t]{3}{*}{$25^{\circ}$} & $375-410$ & $410-465$ & $600-640$ & $460-580$ & $470-530$ & $530-590$ \\
\hline & $465-510$ & $510-580$ & & & $590-650$ & \\
\hline & $580-610$ & & & & & \\
\hline
\end{tabular}

$$
\begin{aligned}
& \frac{\tanh \left(\omega h \sqrt{\frac{1}{c_{L}^{2}}-\frac{1}{c_{P}^{2}}}\right)}{\tanh \left(\omega h \sqrt{\frac{1}{c_{L}^{2}}-\frac{1}{c_{S}^{2}}}\right)}=\frac{\left(\frac{2}{c_{L}^{2}}-\frac{1}{c_{S}^{2}}\right)^{2}}{\frac{4}{c_{L}^{2}} \sqrt{\frac{1}{c_{L}^{2}}-\frac{1}{c_{P}^{2}} \sqrt{\frac{1}{c_{L}^{2}}-\frac{1}{c_{S}^{2}}}}} \\
& \frac{\tanh \left(\omega h \sqrt{\frac{1}{c_{L}^{2}}-\frac{1}{c_{P}^{2}}}\right)}{\tanh \left(\omega h \sqrt{\frac{1}{c_{L}^{2}}-\frac{1}{c_{S}^{2}}}\right)}=\frac{\frac{4}{c_{L}^{2}} \sqrt{\frac{1}{c_{L}^{2}}-\frac{1}{c_{P}^{2}}} \sqrt{\frac{1}{c_{L}^{2}}-\frac{1}{c_{S}^{2}}}}{\left(\frac{2}{c_{L}^{2}}-\frac{1}{c_{S}^{2}}\right)^{2}},
\end{aligned}
$$

where $\omega$ is the angular frequency $(\omega=2 \pi f)$ of the propagating wave; the signal frequency $f$ is in $\mathrm{MHz}$, and $\omega$ is in $\mathrm{rad} / \mu \mathrm{s} . h$ is one-half of the plate thickness in $\mathrm{mm}, c_{P}$ and $c_{S}$ are the $P$-wave speed and $S$-wave speed in the plate material, respectively, and $c_{L}$ is the phase velocity of the propagating Lamb wave modes. All velocities are in $\mathrm{km} / \mathrm{s}$. Equations (1a) and (1b) correspond to the symmetric and antisymmetric Lamb modes, respectively. Dispersion curves generated by Eq. (1) are shown in Fig. 8.

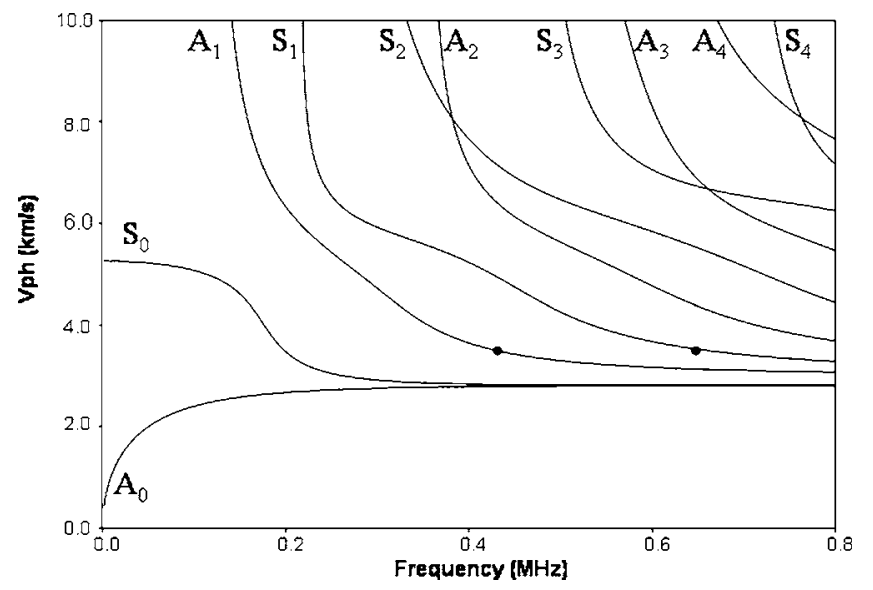

FIG. 8. Dispersion curves of $0.5 \mathrm{in} .(12.7 \mathrm{~mm})$ thick aluminum plate $\left(c_{P}\right.$ $=6.2 \mathrm{~km} / \mathrm{s}, c_{S}=3 \mathrm{~km} / \mathrm{s}$, and $\rho=2.7 \mathrm{gm} / \mathrm{cc}$ ). Two black circles are the experimental data points corresponding to the two peaks at $430 \mathrm{kHz}$ and $645 \mathrm{kHz}$ in the $V(f)$ curve of Fig. 5, corresponding phase velocity $V_{\mathrm{ph}}$ $=3.526 \mathrm{~km} / \mathrm{s}$ for $25^{\circ}$ angle of incidence is obtained from Snell's law [Eq. (2)]. Antisymmetric and symmetric modes of order $m$ are denoted by $A_{m}$ and $S_{m}$, respectively.
The incident angle for the $V(f)$ curves of Fig. 5 is $25^{\circ}$. Therefore, the corresponding phase velocity from Snell's law is

$$
c_{L}=\frac{c_{f}}{\sin \theta}=\frac{1.49}{\sin (25)}=3.526 \mathrm{~km} / \mathrm{s},
$$

where $c_{f}$ is the acoustic wave speed in water $(=1.49 \mathrm{~km} / \mathrm{s})$ and $\theta$ is the incident angle $\left(=25^{\circ}\right)$. Therefore, two peaks of Fig. 5 correspond to two points in the frequency-phase velocity plot of Fig. 8. The horizontal and vertical coordinates of these points are $(430 \mathrm{kHz}, 3.526 \mathrm{~km} / \mathrm{s})$ and $(645 \mathrm{kHz}, 3.526 \mathrm{~km} / \mathrm{s})$. These points are plotted in Fig. 8 by solid circles. Note that they coincide with the $A_{1}$ (first antisymmetric) and $S_{1}$ (first symmetric) modes. Thus, the reliability of the experimental $V(f)$ plots is established.

\section{F. Dispersion curves for corrugated plates}

Banerjee and Kundu (2006) presented a theoretical solution of elastic wave propagation in sinusoidal corrugated plates as shown in Fig. 9. Their approach is not based on the perturbation theory and can be applied equally well to both small and large corrugations. They obtained the dispersion equation by applying the traction-free boundary conditions. Solution of the dispersion equation gives both symmetric and antisymmetric modes. In a periodically corrugated waveguide, all possible spectral orders of wave numbers were considered for the analytical solution. It was observed that the truncation of the spectral order influenced the results. The

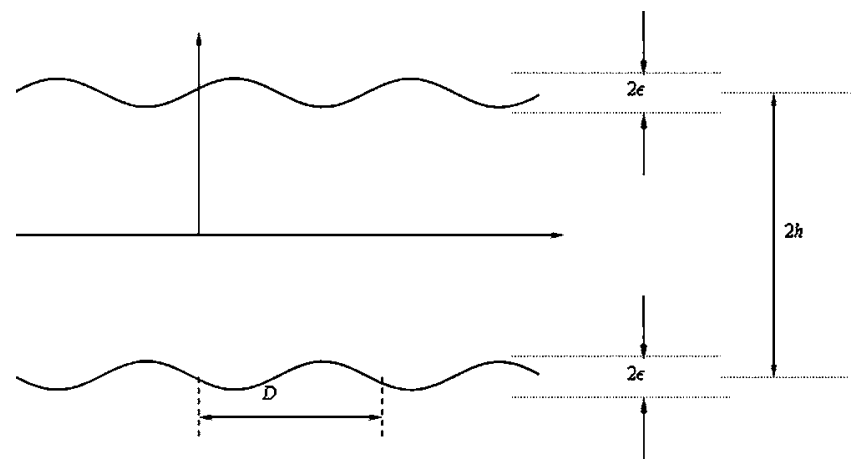

FIG. 9. Corrugated plate geometry with sinusoidal boundaries considered for the theoretical analysis. $D=$ corrugation period, $\varepsilon=$ corrugation depth, and $2 h=$ average plate thickness. 
truncation number depends on the degree of corrugation and the frequency of the wave. Usually, increasing frequency requires increasing the number of terms in the series solution, or in other words, a higher truncation number. The dispersion equation for such plates with periodic boundary geometry can be written as

$$
\operatorname{Det}[\mathbf{T}]=0 .
$$

The dimension of the matrix $\mathbf{T}$ is $(2 \bmod (n)+1) \times(2 \bmod (n)$ +1 ), where $n$ is the number of wave numbers developed for each frequency in the sinusoidally corrugated plate. If $n$ varies from -1 to +1 , the elements of the $\mathbf{T}$ matrix can be written as (Banerjee and Kundu, 2006)

$$
\begin{aligned}
& B C 1_{n p}^{+}=-2 \mu\left(k_{n} \eta_{n}\right)\left\lfloor D e^{\left.i h \eta_{n}\left(J_{0}\left(\varepsilon \eta_{n}\right)+i H_{0}\left(\varepsilon \eta_{n}\right)\right)\right],}\right.
\end{aligned}
$$

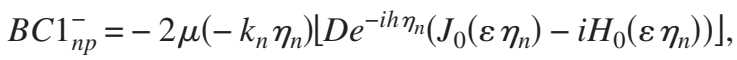

$$
\begin{aligned}
& B C 1_{n s}^{+}=\mu\left(k_{n}^{2}-\beta_{n}^{2}\right)\left[D e^{\left.i h \beta_{n}\left(J_{0}\left(\varepsilon \beta_{n}\right)+i H_{0}\left(\varepsilon \beta_{n}\right)\right)\right],}\right. \\
& B C 1_{n s}^{-}=\mu\left(k_{n}^{2}-\beta_{n}^{2}\right)\left[D e^{-i h \beta_{n}}\left(J_{0}\left(\varepsilon \beta_{n}\right)-i H_{0}\left(\varepsilon \beta_{n}\right)\right)\right], \\
& B C 2_{n p}^{+}=\left[\lambda\left(-k_{n}^{2}-\eta_{n}^{2}\right)+2 \mu\left(-\eta_{n}^{2}\right)\right]\left[D e ^ { i h \eta _ { n } } \left(J_{0}\left(\varepsilon \eta_{n}\right)\right.\right. \\
& \left.\left.+i H_{0}\left(\varepsilon \eta_{n}\right)\right)\right] \\
& B C 2_{n p}^{-}=\left[\lambda\left(-k_{n}^{2}-\eta_{n}^{2}\right)+2 \mu\left(-\eta_{n}^{2}\right)\right]\left[D e ^ { - i h \eta _ { n } } \left(J_{0}\left(\varepsilon \eta_{n}\right)\right.\right. \\
& \left.\left.-i H_{0}\left(\varepsilon \eta_{n}\right)\right)\right] \text {, } \\
& B C 2_{n s}^{+}=2 \mu\left(k_{n} \beta_{n}\right)\left\lfloor D e^{\left.i h \beta_{n}\left(J_{0}\left(\varepsilon \beta_{n}\right)+i H_{0}\left(\varepsilon \beta_{n}\right)\right)\right\rfloor,}\right. \\
& B C 2_{n s}^{-}=-2 \mu\left(k_{n} \beta_{n}\right)\left\lfloor D e^{\left.-i h \beta_{n}\left(J_{0}\left(\varepsilon \beta_{n}\right)-i H_{0}\left(\varepsilon \beta_{n}\right)\right)\right\rfloor,}\right. \\
& B C 3_{n p}^{+}=2 \mu\left(k_{n} \eta_{n}\right)\left\lfloor D e^{-i h \eta_{n}}\left(J_{0}\left(\varepsilon \mu_{n}\right)-i H_{0}\left(\varepsilon \eta_{n}\right)\right)\right], \\
& B C 3_{n p}^{-}=-2 \mu\left(k_{n} \eta_{n}\right)\left\lfloor D e^{\left.i h \eta_{n}\left(J_{0}\left(\varepsilon \mu_{n}\right)+i H_{0}\left(\varepsilon \eta_{n}\right)\right)\right\rfloor,}\right.
\end{aligned}
$$

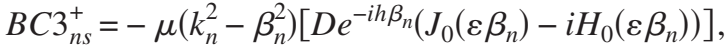

$$
\begin{aligned}
& B C 3_{n s}^{-}=-\mu\left(k_{n}^{2}-\beta_{n}^{2}\right)\left[D e^{\left.i h \beta_{n}\left(J_{0}\left(\varepsilon \beta_{n}\right)+i H_{0}\left(\varepsilon \beta_{n}\right)\right)\right],}\right. \\
& B C 4_{n p}^{+}=\left[\lambda\left(k_{n}^{2}+\eta_{n}^{2}\right)+2 \mu\left(\eta_{n}^{2}\right)\right]\left[D e^{-i h \eta_{n}\left(J_{0}\left(\varepsilon \eta_{n}\right)\right.}\right. \\
& \left.\left.-i H_{0}\left(\varepsilon \eta_{n}\right)\right)\right] \text {, } \\
& B C 4_{n p}^{-}=\left[\lambda\left(k_{n}^{2}+\eta_{n}^{2}\right)+2 \mu\left(\eta_{n}^{2}\right)\right]\left[D e^{i h \eta_{n}\left(J_{0}\left(\varepsilon \eta_{n}\right)\right.}\right. \\
& \left.\left.+i H_{0}\left(\varepsilon \eta_{n}\right)\right)\right] \text {, } \\
& B C 4_{n s}^{+}=-2 \mu\left(k_{n} \beta_{n}\right)\left\lfloor D e^{-i h \beta_{n}}\left(J_{0}\left(\varepsilon \beta_{n}\right)-i H_{0}\left(\varepsilon \beta_{n}\right)\right)\right\rfloor, \\
& B C 4_{n s}^{-}=2 \mu\left(k_{n} \beta_{n}\right)\left\lfloor D e^{\left.i h \beta_{n}\left(J_{0}\left(\varepsilon \beta_{n}\right)+i H_{0}\left(\varepsilon \beta_{n}\right)\right)\right\rfloor,}\right.
\end{aligned}
$$

where the Struve function $H_{n}(z)$ appears in the solution of the inhomogeneous Bessel equation which for integer $n$ has the form
Low Corrugation (Specimen \#1)
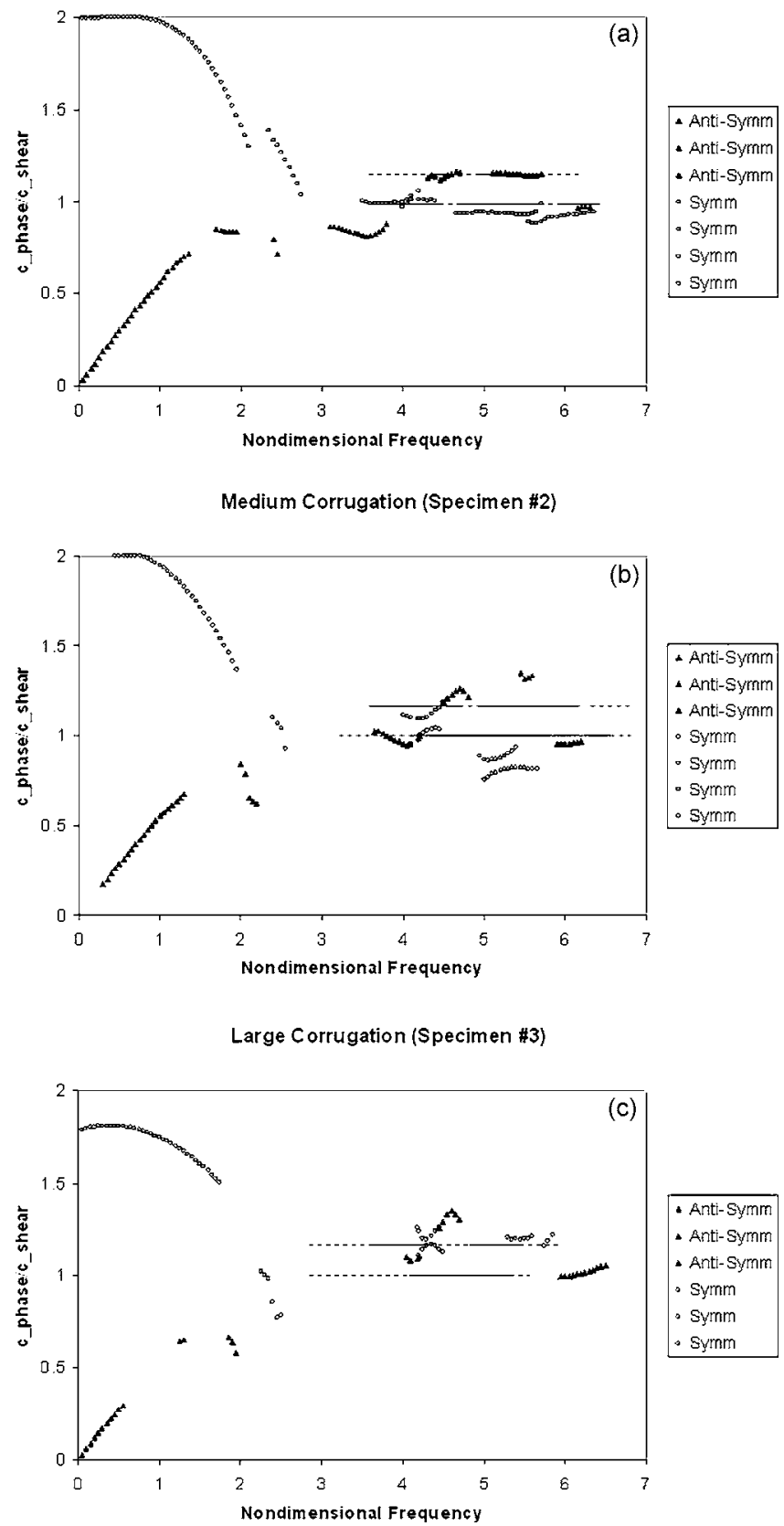

FIG. 10. Symmetric (circles) and antisymmetric (triangles) modes computed theoretically from Eq. for three plate specimens [(a) - small corrugation, Specimen No. 1; (b)—medium corrugation, Specimen No. 2; and (c)—large corrugation, Specimen No. 3]. See Table I for specimen dimensions. Experimentally obtained stop bands (dashed lines) and pass bands (continuous lines) for two normalized phase velocities $\left(0.993\right.$ corresponds to $30^{\circ}$ striking angle and 1.175 for $25^{\circ}$ striking angle) are shown in each plot. In (a), pass bands match very well with the theoretical values. However, the matching between the theoretical and experimental values is not as good in (b) and (c).

$$
z^{2} \frac{d^{2} y}{d z^{2}}+z \frac{d y}{d z}+\left(z^{2}-n^{2}\right) y=\frac{2}{\pi} \frac{z^{n+1}}{(2 n-1) ! !},
$$

the general solution of this equation consists of a linear combination of the Bessel functions $J_{n}(z)$ and the Struve functions $H_{n}(z)$.

Although the plate boundaries considered in the experiment are not pure sinusoidal, the geometry, shown in Fig. 9, 
TABLE III. Nondimensional frequencies $(\Omega)$ for stop and pass bands for two striking angles and three corrugated plate specimens, whose dimensions are given in Table I.

\begin{tabular}{|c|c|c|c|c|}
\hline Striking angle $(\theta)$ & $30^{\circ}$ & $30^{\circ}$ & $25^{\circ}$ & $25^{\circ}$ \\
\hline$\frac{c_{L}}{c_{S}}=\frac{(1.49 / \sin \theta)}{3}$ & 0.993 & 0.993 & 1.175 & 1.175 \\
\hline Specimen No. 1 & $\begin{array}{l}\text { Stop band } \\
\text { frequency } \\
(\mathrm{MHz})\end{array}$ & $\begin{array}{l}\text { Pass band } \\
\text { frequency } \\
(\mathrm{MHz})\end{array}$ & $\begin{array}{l}\text { Stop band } \\
\text { frequency } \\
(\mathrm{MHz})\end{array}$ & $\begin{array}{l}\text { Pass band } \\
\text { frequency } \\
(\mathrm{MHz})\end{array}$ \\
\hline $\begin{array}{l}\text { Frequency }(f) \text { range } \\
\text { (in } \mathrm{MHz} \text { ) }\end{array}$ & $\begin{array}{l}0.370-0.390 \\
0.470-0.490\end{array}$ & $\begin{array}{l}0.300-0.370 \\
0.390-0.470 \\
0.490-0.650\end{array}$ & $\begin{array}{l}0.300-0.350 \\
0.375-0.410 \\
0.465-0.510 \\
0.580-0.610\end{array}$ & $\begin{array}{l}0.350-0.375 \\
0.410-0.465 \\
0.510-0.580\end{array}$ \\
\hline $\begin{array}{l}\text { Nondimensional frequency } \\
(\Omega)\end{array}$ & $4.51-4.75$ & $3.65-4.51$ & $3.65-4.26$ & $4.26-4.57$ \\
\hline$\left(\Omega=\frac{2 \pi f h}{c_{S}}=\frac{11.63 \pi f}{3}=12.18 f\right)$ & $5.72-5.97$ & $\begin{array}{l}4.75-5.72 \\
5.97-7.92\end{array}$ & $\begin{array}{l}4.57-4.99 \\
5.66-6.21 \\
7.06-7.43\end{array}$ & $\begin{array}{l}4.99-5.66 \\
6.21-7.06\end{array}$ \\
\hline Specimen No. 2 & $\begin{array}{l}\text { Stop band } \\
\text { frequency } \\
(\mathrm{MHz})\end{array}$ & $\begin{array}{l}\text { Pass band } \\
\text { frequency } \\
(\mathrm{MHz})\end{array}$ & $\begin{array}{l}\text { Stop band } \\
\text { frequency } \\
(\mathrm{MHz})\end{array}$ & $\begin{array}{l}\text { Pass band } \\
\text { frequency } \\
(\mathrm{MHz})\end{array}$ \\
\hline $\begin{array}{l}\text { Frequency }(f) \text { range } \\
\text { (in } \mathrm{MHz} \text { ) }\end{array}$ & $\begin{array}{l}0.300-0.380 \\
0.620-0.645\end{array}$ & $\begin{array}{l}0.380-0.620 \\
0.645-0.680\end{array}$ & $\begin{array}{l}0.440-0.460 \\
0.600-0.640\end{array}$ & $\begin{array}{l}0.340-0.440 \\
0.460-0.580\end{array}$ \\
\hline $\begin{array}{l}\text { Nondimensional frequency } \\
(\Omega)\end{array}$ & $3.19-4.04$ & $4.04-6.56$ & $4.68-4.89$ & $3.61-4.68$ \\
\hline$\left(\Omega=\frac{2 \pi f h}{c_{S}}=\frac{10.16 \pi f}{3}=10.64 f\right)$ & $6.56-6.86$ & $6.86-7.24$ & $6.38-6.81$ & $4.89-6.17$ \\
\hline Specimen No. 3 & $\begin{array}{l}\text { Stop band } \\
\text { frequency } \\
(\mathrm{MHz})\end{array}$ & $\begin{array}{l}\text { Pass band } \\
\text { frequency } \\
(\mathrm{MHz})\end{array}$ & $\begin{array}{l}\text { Stop band } \\
\text { frequency } \\
(\mathrm{MHz})\end{array}$ & $\begin{array}{l}\text { Pass band } \\
\text { frequency } \\
(\mathrm{MHz})\end{array}$ \\
\hline $\begin{array}{l}\text { Frequency }(f) \text { range } \\
\text { (in } \mathrm{MHz} \text { ) }\end{array}$ & $\begin{array}{l}0.300-0.450 \\
0.580-0.600\end{array}$ & $0.450-0.580$ & $\begin{array}{l}0.300-0.390 \\
0.470-0.530 \\
0.590-0.650\end{array}$ & $\begin{array}{l}0.390-0.470 \\
0.530-0.590\end{array}$ \\
\hline $\begin{array}{l}\text { Nondimensional stop band } \\
\text { frequency }(\Omega)\end{array}$ & $2.75-4.12$ & & $2.75-3.57$ & $3.57-4.30$ \\
\hline$\left(\Omega=\frac{2 \pi f h}{c S}=\frac{8.74 \pi f}{3}=9.15 f\right)$ & $5.35-5.49$ & $4.12-5.31$ & $\begin{array}{l}4.35-4.85 \\
5.40-5.95\end{array}$ & $4.85-5.40$ \\
\hline
\end{tabular}

is the closest geometry to our problem for which theoretical solutions are available today. A comparison between Figs. 2(c) (true plate geometry) and 9 (plate geometry that has analytical solution) shows some common features between these two geometries, such as both plates have a periodicity with wavelength $D$, both have a maximum plate thickness $H_{1}$, and a minimum plate thickness $H_{2}$. Then, the average plate thickness $2 h$ is $\left(H_{1}+H_{2}\right) / 2$ and the corrugation depth $2 \varepsilon=\left(H_{1}-H_{2}\right) / 2$.

Analytically computed dispersion curves for the fundamental symmetric and antisymmetric modes for the three plate geometries with $2 h / D$ ratio equal to $1.078,1.081$, 0.905 , and the corresponding $\varepsilon / D$ ratio equal to 0.049 , 0.135 , and 0.205, respectively, are shown in Fig. 10. It should be noted here that although the geometry (Fig. 9) for the analytical solution is different from the specimen geometries (Fig. 2), two important parameters $(2 h / D$ and $\varepsilon / D)$ are the same for the analytical solution and the experimental investigation (listed in the right two columns of Table I). Three plate geometries for the analytical solution are denoted as Specimens 1, 2, and 3; similar to the three-plate specimens described in Table I. Figure 10 shows the analytically computed dispersion curves for the three corrugated plates.
In Fig. 10, the phase velocity is normalized with respect to the shear wave speed $(3 \mathrm{~km} / \mathrm{s})$ in the plate material. The nondimensional frequency $(\Omega)$ plotted along the horizontal axis is defined as

$$
\Omega=\frac{\omega h}{c_{S}}
$$

where $\omega, h$, and $c_{S}$ are identical to those in Eq. (1).

In the dispersion curves of Fig. 10, one can observe several discontinuities that are not observed in the dispersion curves for a smooth plate (see Fig. 8). The gaps in the dispersion curves are called the stop bands. It is interesting to note that as the corrugation depth increases, the extent of the stop bands also increases. Experimentally, it is also observed that the stop band zones increase with the corrugation depth, see Figs. 6 and 7-it gives a qualitative agreement between the experimental observations and theoretical predictions. For a quantitative comparison between the experimental and theoretical results, the nondimensional frequency $(\Omega)$ and the normalized phase velocity $c_{L} / c_{S}$ corresponding to the stop bands and pass bands shown in Table II, are calculated and listed in Table III. 
As shown in Table III, $c_{L} / c_{S}$ is 0.993 and 1.175 for the $30^{\circ}$ and $25^{\circ}$ angles of incidence, respectively. When the pass band and stop band frequencies are transformed from $\mathrm{kHz}$ (or $\mathrm{MHz}$ ) to a nondimensional frequency $(\Omega)$ using Eq. (6), then the stop band of $370-390 \mathrm{kHz}$ for Specimen No. 1 is changed to 4.51-4.75, as shown in Table III. When these stop bands (dashed lines) and pass bands (continuous lines) are plotted on the dispersion curves of Fig. 10, then sometimes good matching and discrepancies between the theoretical curves and experimental stop and pass bands are observed. Since experiments are carried out for two different incident angles that correspond to two different $c_{L} / c_{S}$ values (0.993 and 1.175), we get two horizontal lines corresponding to these two normalized velocities, as shown in each plot of Fig. 10.

In Fig. 10(a), experimental stop bands (dashed lines) and pass bands (continuous lines) match very well with the theoretical dispersion curves. Note that the continuous lines either coincide or are located very close to the triangles (antisymmetric modes) or circles (symmetric modes), while the dashed lines are seen in the regions where neither circles nor triangles are present. However, the matching between the experimental data (horizontal continuous lines at $c_{L} / c_{S}$ $=0.993$ and 1.175) and the theoretical values (triangles and circles) are not as good in Figs. 10(b) and 10(c). The only matching that can be highlighted here is that, in Fig. 10(c) in the nondimensional frequency range from 2.5 to 3.5 , both theoretical and experimental values show stop bands.

From Fig. 10 it can be concluded that for small corrugation depth (when the $\varepsilon / D$ ratio is less than or equal to $0.05)$ the assumption of sinusoidal corrugation geometry is acceptable even when the actual geometry is not sinusoidal but periodic; however, for large corrugation depth $(\varepsilon / D$ $>0.1$ ) the sinusoidal corrugation assumption does not work very well when the actual corrugation geometry is not sinusoidal.

\section{CONCLUSION}

The elastic wave propagation in homogeneous plates with periodic corrugated boundaries is experimentally investigated in this paper. Guided waves in three plates with three different degrees of corrugation are studied. Different stop bands and pass bands are observed for the three plates. The extent of stop bands is found to increase with the depth of corrugation. Experimental data generated by nonsinusoidal corrugated plates are compared with the theoretical predictions for sinusoidal corrugated plates. For a small corrugation depth, the theoretical and experimental data match reasonably well. However, for a large corrugation depth, the matching is not as good-indicating that, for large degree of corrugation, the exact geometry of the plate boundary needs to be incorporated in the model. Only two parameters-the wavelength of periodicity and the depth of corrugation-are enough for correctly predicting the pass band and stop band regions in plates with a small degree of corrugation, but these two parameters are not enough for modeling wave propagation in plates with a large degree of corrugation.

\section{ACKNOWLEDGMENTS}

This research was partially supported from a research grant from the Air Force Research Laboratory, AFRL/MLLP, through CNDE (Center for Nondestructive Evaluation) of the Iowa State University and a grant from the National Science Foundation under Contract No. CMS-9901221. The authors would also like to acknowledge the technical help of Mr. R. Reibel and Dr. S. Sathish of UDRI/MLLP while carrying out the experiments.

Banerjee, S., and Kundu, T. (2004). "Elastic wave propagation in symmetrically periodic sinusoidal waveguide," Proc. SPIE 5394, 89-98.

Banerjee, S., and Kundu, T. (2006). "Symmetric and antisymmetric Rayleigh-Lamb modes in sinusoidally corrugated waveguides: An analytical approach," Int. J. Solids Struct. (in press).

Boström, A. (1983). "Passbands and stopbands for an electromagnetic waveguide with a periodically varying cross section," IEEE Trans. Microwave Theory Tech. 31, 752-756.

Boström, A. (1989). "Propagating, damped, and leaky surface waves on the corrugated traction-free boundary of an elastic half-space," J. Acoust. Soc. Am. 85, 1549-1555.

Brillouin, L. (1946). Wave Propagation in Periodic Structures (Dover, New York).

Declercq, N. F., Degrieck, J., Briers, R., and Leroy, O. (2005). "Diffraction of homogeneous and inhomogeneous plane waves on a doubly corrugated liquid/solid interface," Ultrasonics 43, 605-618.

El-Bahrawy, A. (1994a). "Stopbands and passbands for symmetric Rayleigh-Lamb modes in a plate with corrugated surfaces," J. Sound Vib. 170, 145-160.

El-Bahrawy, A. (1994b). "Point force excitation of surface waves along the doubly corrugated traction-free boundary of an elastic half-space," J. Acoust. Soc. Am. 96, 3167-3176.

Fokkema, J. H. (1980). "Reflection and transmission of elastic waves by the spatially periodic interface between two solids (Theory of integralequation method)," Wave Motion 2, 375-393.

Glass, N. E., and Maradudin, A. A. (1983). "Leaky surface-elastic waves on both flat and strongly corrugated surfaces for isotropic, nondissipative media," J. Appl. Phys. 54, 796-805.

Kundu, T. (editor) (2004). Ultrasonic Nondestructive Evaluation: Engineering and Biological Material Characterization (CRC Press, Boca Raton, FL), Chap. 1, pp. 1-142.

Mead, D. J. (1970). "Free wave propagation in periodically supported, infinite beams," J. Sound Vib. 11, 181-197.

Mead, D. J. (1975). "Wave propagation and normal modes in periodic systems: 1. Monocoupled systems," J. Sound Vib. 40, 1-18.

Mead, D. J. (1976). "Loss factors and resonant frequencies of periodic damped sandwiched plates," ASME J. Eng. Ind. 98, 75-80.

Mead, D. J. (1986). "A new method of analyzing wave propagation in periodic structures: Applications to periodic Timoshenko beams and stiffened plates," J. Sound Vib. 104, 9-27.

Mead, D. J., and Markus, S. (1983). "Coupled flexural-longitudinal wave motion in a periodic beam," J. Sound Vib. 90, 1-24.

Mead, D. J., and Bardell, N. S. (1987). "Free vibration of thin cylindrical shell with periodic circumferential stiffeners," J. Sound Vib. 115, 499521

Mead, D. J., and Yaman, Y. (1991). "The harmonic response of rectangular sandwich plates with multiple stiffening: A flexural wave analysis," J. Sound Vib. 145, 409-428.

Mester, S. S., and Benaroya, H. (1995). "Periodic and near-periodic structures," J. Sound Vib. 2, 69-95.

Nayfeh, A. H., and Kandil, O. A. (1978). "Propagation waves in cylindrical hard-walled ducts with generally weak undulations," AIAA J. 16, 10411045.

Orris, R. M., and Petyt, M. (1974). "A finite element study of harmonic wave propagation in periodic structures," J. Sound Vib. 33, 223-236.

Russene, M., and Baz, A. (2000). "Control of wave propagation in periodic 
composite rods using shape memory inserts," J. Vibr. Acoust. 122, 151159.

Sandström, S. E. (1986). "Stop bands in a corrugated parallel-plate waveguide," J. Acoust. Soc. Am. 79, 1293-1298.
Vasseur, J. O., Deymier, P. A., Frantziskonis, G., Hong, G., Djafari-Rouhani, B., and Dobrzynski, L. (1998). "Experimental evidence for the existence of absolute acoustic band gaps in two-dimensional periodic composite media," J. Phys.: Condens. Matter 10, 6051-6064. 